\title{
Hypoallergenic Legume Crops and Food Allergy: Factors Affecting Feasibility and Risk
}

\author{
John J. Riascos, ${ }^{\dagger}{ }^{\S}$ Arthur K. Weissinger, ${ }^{\dagger}$ Sandra M. Weissinger,${ }^{\dagger}$ And \\ A. Wesley BurKs*,§ \\ ${ }^{\dagger}$ Department of Crop Science, North Carolina State University, Raleigh, North Carolina 27695 and \\ ${ }^{\S}$ Pediatric Allergy and Immunology, Duke University Medical Center, Durham, North Carolina 27710
}

\begin{abstract}
Currently, the sole strategy for managing food hypersensitivity involves strict avoidance of the trigger. Several alternate strategies for the treatment of food allergies are currently under study. Also being explored is the process of eliminating allergenic proteins from crop plants. Legumes are a rich source of protein and are an essential component of the human diet. Unfortunately, legumes, including soybean and peanut, are also common sources of food allergens. Four protein families and superfamilies account for the majority of legume allergens, which include storage proteins of seeds (cupins and prolamins), profilins, and the larger group of pathogenesis-related proteins. Two strategies have been used to produce hypoallergenic legume crops: (1) germplasm lines are screened for the absence or reduced content of specific allergenic proteins and (2) genetic transformation is used to silence native genes encoding allergenic proteins. Both approaches have been successful in producing cultivars of soybeans and peanuts with reduced allergenic proteins. However, it is unknown whether the cultivars are actually hypoallergenic to those with sensitivity. This review describes efforts to produce hypoallergenic cultivars of soybean and peanut and discusses the challenges that need to be overcome before such products could be available in the marketplace.
\end{abstract}

KEYWORDS: Legume allergens; food allergies; hypoallergenic crops; soybean; peanut

\section{INTRODUCTION}

The Fabaceae or legume family of plants accounts for $27 \%$ of primary crop production worldwide and is second in importance only to the cereal grasses (1). Legume seeds are a rich source of protein and an important source of vegetable oil. In most species, seed protein content varies from 20 to $30 \%$ of total dry weight. Oil content is more variable, ranging from $1 \%$ (e.g., lentil) to approximately 50\% (e.g., peanut) (2). Legumes are an essential constituent of human diets, contributing a third of both dietary protein and processed vegetable oil for human consumption (1). Additionally, legumes are important sources of animal feeds and industrial oils (3).

Despite their nutritional value, legumes are also an important source of food allergens. Food allergies affect approximately $6 \%$ of children and $3-4 \%$ of adults in the United States (4). Legumes contribute significantly to these numbers, with peanut allergy affecting $>1 \%$ of children and $0.6 \%$ of adults $(4,5)$ and soybean allergy affecting approximately $0.4 \%$ of children in the United States (5). In addition, allergenic food proteins have been identified in nearly all of the most important legume crops, including lentil (Lens culinaris), common bean (Phaseolus vulgaris), mungbean (Vigna radiata), chickpea (Cicer arietinum),

*Corresponding author [telephone (919) 681-2949; fax (919) 6683750; e-mailwesley.burks@duke.edu]. and pea (Pisum sativum) (Table 1). Unfortunately, there are no estimates of the prevalence of other legume allergies.

Most of the food allergens characterized to date range in molecular mass from 10 to $70 \mathrm{kDa}(6)$, and no single characteristic has been identified as determining allergenicity. Importantly, characteristics such as structural stability and overall abundance are often considered when allergenic potential is predicted (7). A protein that is stable under different conditions (e.g., resistant to heat denaturation or protease degradation) is more likely to go through mucosal barriers and induce allergic reaction than one that is degraded in the digestive tract $(7,8)$. In general, the abundance of a particular protein is positively correlated with prompt elicitation of allergic response. This observation is supported by the fact that many important food allergens, such as some seed storage proteins (e.g., 7S and $11 \mathrm{~S}$ globulins), are highly abundant proteins. Despite these characteristics contributing to allergenic potential, it is not possible to predict allergenicity of a protein based on these two criteria (7).

Because food allergies can be life threatening, a variety of strategies to abrogate or minimize allergic episodes are currently under study. Significant advances have been achieved with novel forms of immunotherapy, which include homologous protein immunotherapy (9), DNA plasmid immunizations (10), sublingual and oral immunotherapy, $(11,12)$, and anti-IgE immunotherapy (13). However, none of these treatments has yet advanced to clinical practice. 
An alternative strategy to minimize allergic reactions, often caused by accidental contact with the offending food source, involves eliminating allergenic proteins both from leguminous crop plants and from processed foods prepared from legumes. The development of genetic stocks with a reduced or "null" content of allergenic proteins is a strategy that has been intensified during the past 10 years and is considered to be promising for management of food allergies $(14,15)$. However, this approach is limited by several factors, including the potential risk of sensitization to newly overexpressed proteins and questions regarding the long-term stability of transgenic suppression of allergenic proteins. Consumer acceptance and regulatory difficulties, often associated with genetically modified organisms (GMOs), may also limit this strategy.

Here, we present an overview of the current literature regarding allergenic proteins of legumes. We subsequently discuss the issues associated with the development, deployment, production, and safety of hypoallergenic crops, as well as their potential role in managing legume allergy.

\section{CLASSIFICATION OF LEGUME ALLEGENS}

On the basis of the list of allergens in the allergome database (16-18) and an extensive literature review, we identified 13 protein families among legume species that contain allergenic proteins (Table 1). As is the case for most allergenic plant foods (19), only four protein families and superfamilies account for the majority of legume allergens: the cupins (including the $7 \mathrm{~S}$ and 11S globulins); the cereal prolamin superfamily (composed of nonspecific lipid transfer proteins, nsLTPs, and the $2 \mathrm{~S}$ storage albumins); profilins; and the larger group of pathogenesis-related proteins (mostly composed of homologues of the major birch pollen allergen, Bet v 1). Other protein families, such as oleosins, cysteine proteases, Kunitz trypsin inhibitors, calcium-binding proteins, and the family of seed biotinylated proteins, account for the remaining allergenic proteins in leguminous crops (Table 1). In addition to being a common source of food allergens, legume species can also cause some respiratory allergies through cross-sensitization with proteins from other species. The protein families most often associated with this phenomenon include profilins, homologues of the Bet $v 1$ allergen (PR-10), glucanases (PR-2), and calcium-binding proteins.

In the United States, peanut and soybean are the legumes that most frequently trigger hypersensitivity in patients with food allergies (20), and thus most of the characterized legume allergens belong to these crops. Allergic reactions to peanut are often more severe than those to soybean (20) and more commonly cause anaphylaxis (21). However, soy protein is often used as an additive in commercial foods and is thus very difficult to avoid. Given their importance as sources of food allergens, peanut and soy have been the focus of most attempts to produce hypoallergenic legumes.

\section{HYPOALLERGENIC CROPS}

Currently, no hypoallergenic crops are commercially available, although several attempts have been made to produce germplasm with reduced allergenic content. In nonleguminous crops, such as rice, tomato, and apples, several allergens have been targeted for reduction, including RAP ( $\alpha$-amylase inhibitor) (22), Lyc e 1 (23) and Lyc e 3 (24) (profilin and nsLTP, respectively), and Mal d 1 (PR-10) (25). In legume crops, most efforts have been focused on obtaining varieties with reduced content of P34/Gly m Bd 30K (a cysteine protease) in soybean (26-28) and Ara h 2 (a $2 S$ albumin) in peanut $(15,29,30)$. There have been no reports of attempts to produce other hypoallergenic legume crops. 
Two primary strategies have been used to obtain hypoallergenic legume crops. In the first, germplasm lines are screened for the absence or reduced content of specific allergenic protein(s) $(28,30-33)$. In the second, genetic transformation is used to silence native genes encoding allergenic proteins $(15,27,29)$

Germplasm screenings have been developed at the protein and DNA level. Protein screens have been performed using specific antibodies (monoclonal or polyclonal) that recognize a specific allergen $(28,31)$ or stained gels that evaluate the overall protein profile of the varieties of interest $(32,33)$. In both of these cases the objective has been to identify cultivars with "null" or reduced contents of the target allergen. DNA screens have been developed by means of strategies such as EcoTILLING (30). This strategy relies on the amplification of the gene of interest from a pool of template DNAs that could carry natural mutations (34), and the main objective has been to identify cultivars carrying natural hypoallergenic variants of known allergens.

All varieties produced through genetic transformation have been developed using RNA interference (RNAi) $(15,29)$ or related approaches such as cosuppression (27). Both of these approaches share mechanistic similarities associated with the generation of aberrant double-stranded mRNAs (dsRNAs) that trigger post-transcriptional gene silencing (PTGS) $(35,36)$. In the case of cosuppression, PTGS is induced by a sense transgene that can suppress expression of the transgene as well as the endogenous homologous genes, hence the name cosuppression $(35,36)$. RNAi, on the other hand, conventionally uses antisense transgenes to induce PTGS $(35,36)$. Although other mechanistic differences could be associated with RNAi and cosuppression, a discussion on these intricate differences is outside the scope of this review, and readers are advised to consult other sources $(35,36)$.

It is also important to note that varieties devoid of specific allergenic proteins have been produced using transgenic and nontransgenic approaches and for purposes different other than producing hypoallergenic crops (37-39).

Soybean. Reductions in $\beta$-Conglycinin and Glycinin. $\beta$-Conglycinin (Gly m 5) is a trimeric soybean protein composed of $\alpha$ - (Gly m 5.01), $\alpha^{\prime}$ - (Gly m 5. 02), and $\beta$-subunits (Gly m 5. 03). $\beta$-Conglycinin has low methionine content and undesirable processing properties in the preparation of derived foods such as tofu, which has prompted efforts to reduce it in commercial soybean varieties in Japan (37). The identification of the $\alpha$ subunit as an important allergen also increased interest in decreasing $\beta$-conglycinin from commercial soybean varieties (26).

Japanese germplasm collections contain the soybean cultivars 'Mo-shi-dou' (Gong 503) and 'Keburi', which have reduced levels of $\beta$-conglycinin (40). 'Mo-shi-dou' contains low levels of both the $\alpha$ - and $\beta$-subunits of $\beta$-conglycinin, whereas 'Keburi' is null for the $\alpha^{\prime}$ subunit. $\gamma$-Irradiation of a breeding line derived from 'Mo-shi-dou' and 'Keburi' produced a cultivar deficient in the $\alpha$ - and $\alpha^{\prime}$-subunits of $\beta$-conglycinin (37). The cultivar, named 'Tohoku 124', has low levels of the $\beta$-subunit of $\beta$-conglycinin, but it has increased levels of glycinin, which is also an allergen (Gly m 6) (Table 1). Higher levels of glycinin also have been observed in the parental lines 'Mo-shi-dou' and 'Keburi'.

Given the increased levels of glycinin, it is not clear that soybean varieties with reduced $\beta$-conglycinin are actually hypoallergenic. Yaklich et al. (31) have suggested that accessions of Glycine max containing elevated levels of both glycinin and $\beta$ conglycinin are not necessarily more allergenic than varieties with normal levels of these proteins. However, this observation was based on IgE-binding profiles, and no other allergy related data were generated. Taking into consideration that glycinin is an allergen recognized by the majority of patients with severe soy allergy (41), it remains a question if an increase in this protein represents a higher risk for soy allergic patients with increased sensitivity or if abundance increase could result in a more rapid sensitization in people predisposed to food allergies but who have not yet developed symptoms.

Takahashi et al. (39) has produced a soybean variety that lacked all glycinins and all $\beta$-conglycinin subunits. This variety, QF2, resulted from a cross between a natural mutant lacking $\beta$-conglycinin (QY2) (42) and an inbred line (EnB1) in which glycinin was absent (43). Despite lacking the two major seed storage proteins, QF2 grew, flowered, and reproduced without any obvious abnormalities, suggesting that glycinins and $\beta$-conglycinins are not essential components of soybean seeds. Protein compensation was also observed in QF2; the levels of lipoxygenase, sucrose-binding proteins, lectin, P34, and other proteins were higher than those in the progenitor lines. QF2 contained increased levels of free amino acids, especially arginine, a nitrogen-rich compound. The overproduction may have been stimulated by the reduction of nitrogen associated with the loss of glycinin and $\beta$-conglycinin. Because QF2 has increased P34, it is unlikely that it could be used as a hypoallergenic variety.

In the investigation developed by Takahashi et al. (39), an additional inbred line, EnF2, was also created. This line was devoid of the $\alpha$-and $\alpha^{\prime}$-subunits of $\beta$-conglycinin, as well as all of the subunits of glycinin, but did express low levels of the $\beta$-subunit of $\beta$-conglycinin. EnF2's vegetative and reproductive developments were healthy, and its overall amino acid composition was similar to that of QF2. No data were reported, however, on the overall protein composition and possible compensation of other proteins in this mutant.

As with nontransgenic lines, transgenic soybean varieties with reduced $\beta$-conglycinin levels compensate by synthesizing increased amounts of other proteins. Kinney et al. (38) found that when both the $\alpha$-and $\alpha^{\prime}$-subunits of $\beta$-conglycinin were eliminated in transgenic soybeans by cosuppression, the resulting lines accumulated increased amounts of glycinin, its precursor form, proglycinin, and P34.

Reductions in P34/Gly m Bd 30K. After P34 was characterized as a major soybean allergen (44), soybean varieties deficient in this protein were bred. Jung and Kinney (26) patented hypoallergenic transgenic soybeans with decreased levels of several allergens, including P34. The patent claims that soybean protein products made from these hypoallergenic soybeans should be substantially free of P34, Gly m Bd $28 \mathrm{~K}$, the $\alpha$-subunit of $\beta$-conglycinin, the soybean Kunitz trypsin inhibitor, Gly $\mathrm{m} 2$, Gly m 1.0101, Gly m 1.0102, rGly m 3, and glycinin G1. There are no additional papers addressing these claims.

Herman and collaborators have used cosuppression to reduce P34 expression in soybean cotyledons (Figure 1) (27). Soybean somatic embryos were transformed with a vector containing the entire open reading frame of P34 driven by a seed-specific promoter. In transgenic somatic embryos, P34 was completely eliminated, and it was subsequently absent from the third generation of homozygous plants. The transgenic lines exhibited growth, development, reproduction, seed set, and seed maturation essentially identical to those of wild type controls. The proteomes of wild type and genetically modified soybeans were compared by two-dimensional electrophoresis and mass spectroscopy. In the proteome of the transgenic line in which P34 was absent, no compensatory protein overexpression was observed. Proteins from the transgenic and wild type soybeans were subjected to IgE immunoblot analysis with a serum pool from six soy-allergic individuals, and no differences in binding were observed, apart from P34's absence in the transgenic line. These results indicate that no additional allergenic proteins were 


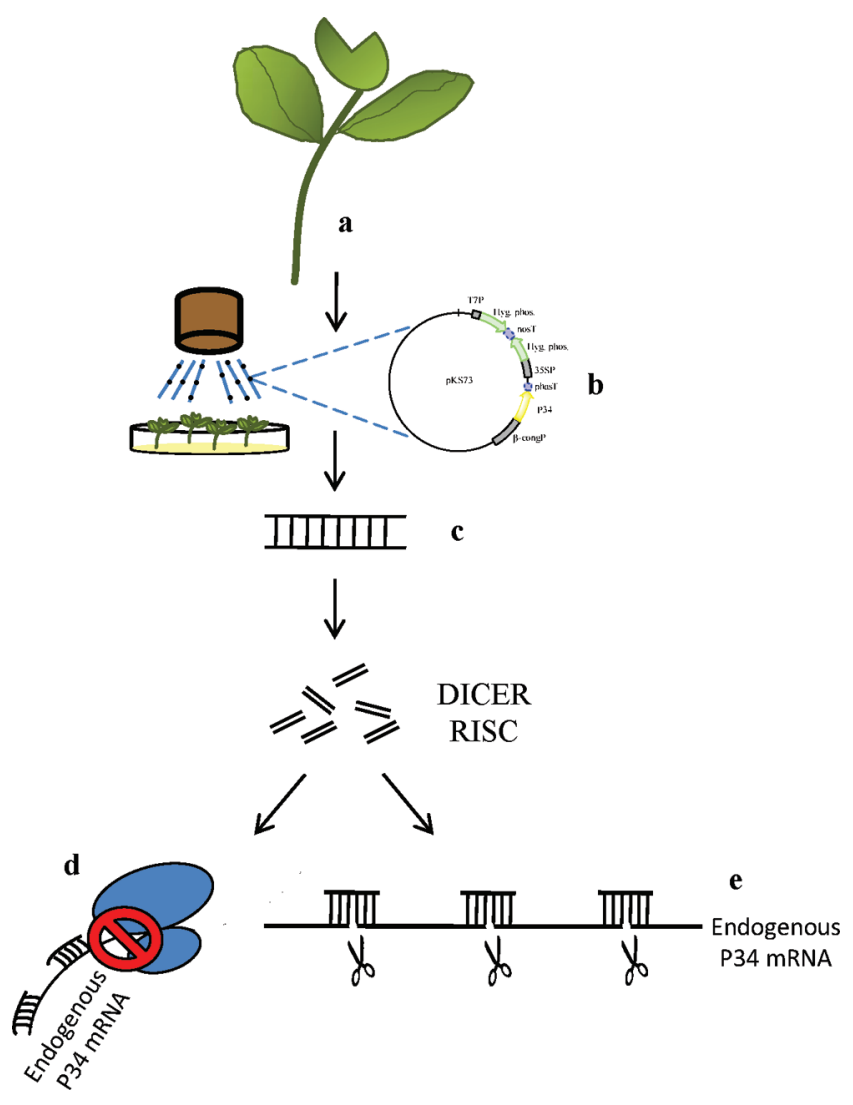

Figure 1. Cosuppression to reduce P34 in soybeans. Using particle bombardment (a), Herman et al. (27) transformed soybean somatic embryos with a plasmid (b) containing the complete P34 open reading frame, in sense, under the control of a $\beta$-conglycinin promoter. dsRNA (c), often formed as a consequence of highly expressed, single-copy transgenes or multiple integrations of a transgene (35), has been associated with activation of PTGS (36). PTGS involves processing of the dsRNAs by proteins such as RISC and DICER. Two possible effector mechanisms of PTGS include translation inhibition (d) and mRNA degradation (e) (36).

produced as a result of the genetic modification to eliminate P34. In vivo experiments in which allergic neonatal pigs are fed foods prepared from transgenic soybeans devoid of P34 were reported to be initiated (45); however, no recent publications describing these results were found in the literature. Although there is evidence that major allergens can be reduced or eliminated by genetic engineering without associated overexpression of other allergenic proteins, the success of this approach will depend on the long-term stability of the gene suppressing expression of P34.

Although the transgenic approach has produced promising results, public resistance to genetically modified products has motivated the search for naturally occurring soybean lines deficient in P34. By screening with a specific antibody for P34, Joseph et al. (28) found 12 lines, of a total of 16,266 accessions of soybean (G. max), wild annual soybean (Glycine soja Sieb. and Zucc.), and wild perennial Glycine species, that were deficient in P34. The two G. $\max$ (PI 567476 and PI 603570A) and the three wild perennial accessions had the lowest levels of P34. Characterization of the G. max accessions revealed that the levels of P34 were $<1 \%$ of the standard levels observed across the soybean collection $(28,31)$. Furthermore, no increases in the levels of any other basic seed proteins were observed in these lines, suggesting that there was no compensation effect. An initial analysis of the P34 cDNA sequence in PI 567476 and PI 603570A led to the hypothesis that an amino acid change, from serine to cysteine, at position 197 resulted in mismatched disulfide bonds in the protein's tertiary structure, affecting its stability-and therefore abundance-in mature seeds. However, recent studies (46) at the genomic level have demonstrated that PI 567476 and PI 603570A contain a four base pair nucleotide insertion at the start codon of the gene. This insertion has been proposed to be the main cause for the reduced levels of P34, although the entire molecular mechanism remains elusive. These studies (46) have also pointed out that efforts to incorporate the mutant P34 gene in elite germplasm have been started. It is not clear, however, whether such minimal protein expression would be tolerated by those with soy hypersensitivity.

Peanuts. Peanut allergy is the most common cause of foodinduced anaphylaxis, and its prevalence appears to be on the rise $(47,48)$. Food allergy due to peanut protein is primarily attributed to three allergens, Ara h 1, Ara h 2, and Ara h 3, which are recognized by $\mathrm{IgE}$ antibodies in the serum of peanut-allergic patients [reviewed in Kang et al. (32)]. Several investigations have focused on obtaining peanut varieties with reduced levels of these proteins.

Koppelman et al. (33) evaluated the protein profiles of 13 individual plants representing the 4 major market types of peanut (Runner, Spanish, Virginia, and Valencia) to determine the presence and abundance of Ara h 1 and Ara h 2. Small differences in abundance of these proteins were observed between the varieties; however, these differences were not statistically significant. In a similar study, Kang et al. (32) examined 60 accessions from the U.S. peanut germplasm collection and 88 lines from the Florida breeding program to evaluate relative amounts of Ara h 1, Ara h 2, and Ara h 3. None of the lines were devoid of any of these allergens, but some varieties had reduced amounts of at least one of them. An accession from India had the lowest level of Ara h 1 , but it also had an elevated level of Ara h 3. Similarly, an accession from Zambia had the lowest level of Ara h 3 but the highest level of Ara h 2. These results suggest a possible compensation effect occurs in peanut as in soybean.

Dodo et al. (15) used RNAi technology to generate plants with reduced levels of Ara h 2 (Figure 2). By transforming peanut cv. 'Georgia Green' with a construct containing a portion of the Ara h 2 gene (in the form of inverted repeats), accumulation of this protein was reduced a maximum of $25 \%$ from its original levels. The overall IgE-binding capacity of crude peanut extracts in the transgenic lines also showed a significant decrease when compared to the control nontransformed plants. Importantly, in this study, the possibility of compensatory overexpression of other proteins was not tested. Furthermore, tests were carried out on a single generation; no data were presented regarding the stability of the transgenic phenotype over multiple generations. Gene suppression by RNAi involves post-transcriptional gene silencing, and this phenomenon may not always be stable over generations (35). However, further studies are in progress to evaluate the allergenic potential and nutritional quality of subsequent generations of transgenic peanut plants (15).

RNAi technology has also been used by Chu et al. (29) to decrease the levels of Ara h 2 and Ara h 6 in peanut plants. Because of the high degree of similarity between the genes, a vector that targeted both allergens was designed. Transformation was carried out via microprojectile bombardment, and gene silencing was tested in more than one generation (generations $\mathrm{T}_{1}$ and $\mathrm{T}_{2}$ ). In general, levels of Ara $\mathrm{h} 2$ and Ara $\mathrm{h} 6$ were significantly reduced, and sera from three different patients with peanut allergy exhibited decreased recognition of these proteins. In addition, there were no significant phenotypic differences (seed weight and germination patterns) observed between transgenic and nontransgenic segregants. Although there were no notable changes in the protein composition of other major allergens 

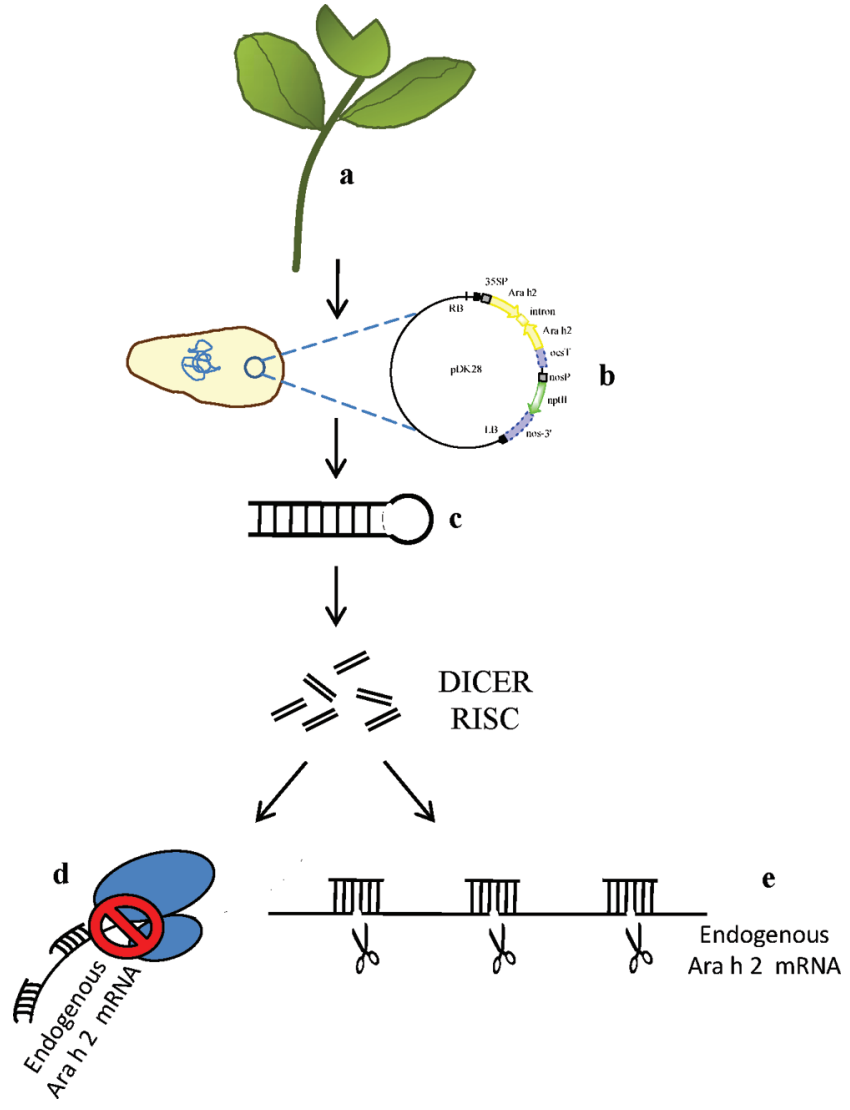

Figure 2. RNAi approach used by Dodo et al. (15) to reduce Ara h 2 in peanuts. Peanut hypocotyls explants (a) were transformed, via A. tumefaciens, with a plasmid containing inverted repeats of a fragment of the Ara h 2 cDNA (b). Inverted repeats, which are responsible for the formation of hairpin-like structures (hpRNA) (c), have been associated with the activation of PTGS (36). PTGS involves processing of the hpRNAs by proteins such as RISC and DICER and effector mechanisms such as translation inhibition (d) and mRNA degradation (e) (36).

(Ara h 1 and Ara h 3 ) in this analysis, a separate investigation by Stevenson et al. (49) detected increased amounts of proteins such as oleosins, lypoxogenase, and arachin (Ara h 3) and decreased amounts of proteins such as conarachin (Ara h 1) in some of these transgenic lines.

Recently (30), EcoTILLING was used to identify hypoallergenic variants of the allergen Ara h 2 in 30 different accessions of Arachis duranensis (a wild relative of Arachis hypogaea and putative donor of one of its ancient genomes) (Figure 3). Ara h/ d 2 was amplified using gene-specific fluorescently labeled primers from a pool of genomic DNA from $A$. duranensis and $A$. hypogaea (Ramos, personal communication). As part of the TILLING process the amplified products are subsequently denatured by heating and allowed to reanneal (randomly) by slow cooling. This process promotes the formation of homoduplexes and/or heteroduplexes in case nucleotide sequence variation exists within the DNA pools analyzed (34). Mismatched base pairs on the double-stranded products are then digested using specific endonucleases, and the fragments generated are sizefractionated and visualized on denaturing polyacrylamide gels (34). As a result of this investigation, five different missense mutations were identified in Ara d 2.01. One of these mutations occurred at the immunodominant epitope 7 and was also correlated with a significant decrease $(56-99 \%)$ in IgE binding. Furthermore, because none of the mutations occurred within the T-cell epitopes characterized for Ara h 2.01, the potential use of this natural hypoallergenic variant for the purpose of immunotherapy was suggested (30). Importantly, producing a commercial peanut variety expressing only the hypoallergenic Ara d 2 gene will be challenging because of the reduced genetic variability present in current accessions of $A$. hypogaea, which contains two isoforms of Ara $\mathrm{h} 2$ and other closely related genes such as Ara h 6.

\section{CONCLUDING REMARKS}

The characterization and development of soybean and peanut lines deficient in specific allergens have provided insight into factors affecting plant protein composition and suggest ways in which transformation could be used to produce crops with reduced allergenicity. However, several concerns must be addressed before hypoallergenic varieties of any crops can be marketed.

The probability of increased allergenicity due to the overabundance of compensatory proteins must be better understood. This issue is especially important because some of the compensatory proteins have been characterized as IgE reactive in the same species or in other closely related species. It is also possible that increased exposure to minor allergens could lead to increased sensitivity. This could even occur in people or livestock without sensitivity to the wild type crop. In this respect it is imperative that the scientific community and regulatory agencies work together in designing standard protocols to evaluate the allergenic potential of these varieties. Current strategies (based on IgE binding) are insufficient to evaluate overall allergenicity and sensitizing capacity caused by altered expression of potentially allergenic proteins. Furthermore, other strategies such as those based on animal models have not been satisfactorily correlated with diverse human allergic sensitization (7) to suspect that we have sufficiently reliable tools to evaluate such changes.

Also a concern is the possibility of reversion, or reappearance of the suppressed trait, through silencing of the transgene. This possibility cannot be overemphasized, because the presence of a transgenic hypoallergenic crop could reduce vigilance among people afflicted with serious allergy. Reappearance of a significant allergen could be dangerous even if reversion involves only a portion of crop populations, because exposure to even small amounts of allergen can have serious consequences for those with severe allergy.

Labeling and promotion of hypoallergenic products must also be tightly controlled. The assertion that a product is no longer allergenic may pose a significant danger to individuals whose allergy is due to proteins other than the eliminated allergens. Legumes produce a broad array of known allergenic proteins. Even though some of these are described as major allergens, all known allergens must be either eliminated or reduced for a crop variety to be viewed as safe. Furthermore, there is mounting evidence that not all potentially allergenic proteins have been characterized. These concerns are especially great regarding the hypoallergenic commodities to be used in manufacturing processed foods. It is critical to educate consumers regarding both the nature of allergens and the production of hypoallergenic crops.

Finally, because crop mixture often occurs in the worldwide food market, it may be extremely difficult to partition a crop into "safe" (hypoallergenic) and "unsafe" (conventional) categories with certainty. Deployment strategies for any potentially hypoallergenic crop must clearly include mechanisms for avoiding accidental mixture or misidentification. Measures could include, for example, contract production of hypoallergenic varieties. Although effective, this strategy would significantly increase commodity costs. 


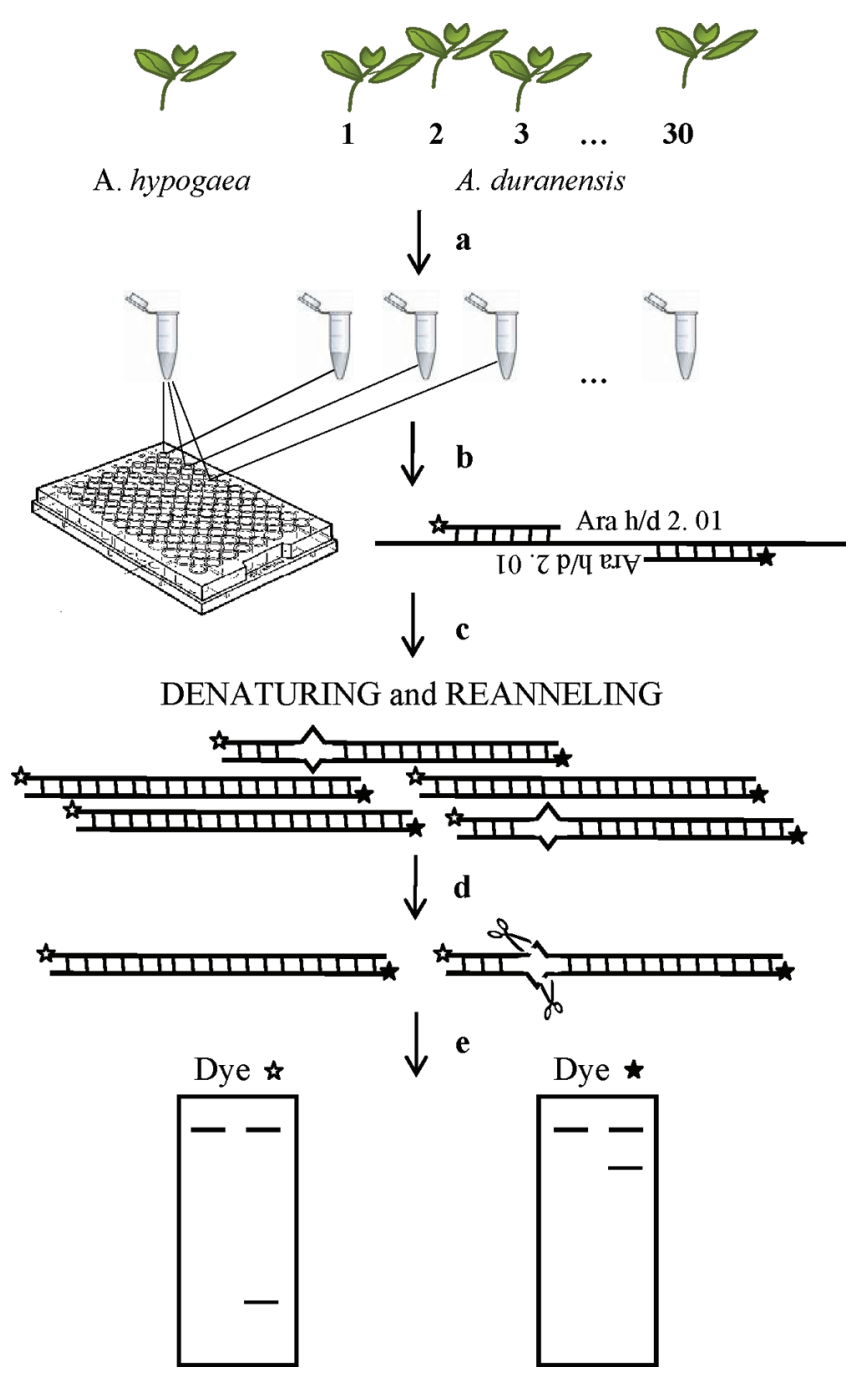

Figure 3. ECOTILLING to identify orthologous hypoallergenic isoforms of Ara $\mathrm{h}$ 2. In the investigation by Ramos et al. (30) genomic DNA was obtained from 30 accessions of $A$. duranensis and from $A$. hypogaea (a). Dual pools of template DNA were generated, and Ara h/d 2 was amplified using fluorescently labeled primers (b). As part of the TILLING process, DNA homoduplexes and/or heteroduplexes were induced by heating and slow cooling (c) (34). Heteroduplexes were then digested with specific endonucleases (d), and the resulting fragmented and nonfragmented products were differentially visualized on polyacrylamide gels (e) (34).

For the reasons discussed above, including possible challenges related to increased allergenicity due to compensatory protein synthesis, reversion of silenced genes, incorrect labeling of plant products, and crop mixture, it is unlikely that production of a hypoallergenic plant will occur soon. It will be interesting, however, to test the feasibility of hypoallergenic crops for the purpose of immunotherapy, because this is a scenario that involves a more controlled environment for the patient. It could be speculated that a crop that lacks allergens or contains reduced amounts of allergens could not induce significant or durable tolerance in patients afflicted by food allergies; however, this is a question that needs to be addressed. Even more interesting will be testing the feasibility of crops such as those identified by Joseph et al. (28) and Ramos et al. (30), for the purpose of therapy. In these varieties, hypoallergenicity is due to natural mutations (isomerism) that affect the production of the allergenic protein or its IgE-binding capacity and do not seem to have an effect on the overall seed protein composition. Because no compensatory proteins are expected, these varieties may be more suited for therapy purposes. All of these studies have now become necessary, and only when more clinical data are produced will we understand the extent of the benefits of hypoallergenic crops.

\section{LITERATURE CITED}

(1) Graham, P. H.; Vance, C. P. Legumes: importance and constraints to greater use. Plant Physiol. 2003, 131, 872-877.

(2) Werner, D. Production and biological nitrogen fixation of tropical legumes. In Nitrogen Fixation in Agriculture, Forestry, Ecology, and the Environment; Dietrich, W., Newton, W., Eds.; Springer: Dordrecht, The Netherlands, 2005; Vol.4, pp 1-13.

(3) Vance, C. P.; Graham, P. H.; Allan, D. L. Biological nitrogen fixation. Phosphorus: a critical future need. In Nitrogen Fixation: From Molecules to Crop Productivity; Pedrosa, F. O., Hungria, M., Yates, M. G., Newton, W. E., Eds.; Kluwer Academic Publishers: Dordrecht, The Netherlands, 2000; pp 506-514.

(4) Sicherer, S. H.; Sampson, H. A. Food allergy: recent advances in pathophysiology and treatment. Annu. Rev. Med. 2009, 60, 261-277.

(5) Sicherer, S. H.; Sampson, H. A. Food allergy. J. Allergy Clin. Immunol. 2006, 117, S470-S475.

(6) Sampson, H. A. Food allergy. Part 1: Immunopathogenesis and clinical disorders. J. Allergy Clin. Immunol. 1999, 103, 717-728.

(7) Goodman, R. E.; Vieths, S.; Sampson, H. A.; Hill, D.; Ebisawa, M.; Taylor, S. L.; van Ree, R. Allergenicity assessment of genetically modified crops - what makes sense. Nat. Biotechnol. 2008, 26, 73-81.

(8) Breiteneder, H.; Mills, E. N. C. Molecular properties of food allergens. J. Allergy Clin. Immunol. 2005, 115, 14-23.

(9) Pons, L.; Ponnappan, U.; Hall, R.; Simpson, P.; Cockrell, G.; West, C. M.; Sampson, H.; Helm, R.; Burks, A. W. Soy immunotherapy for peanut-allergic mice: modulation of the peanut-allergic response. J. Allergy Clin. Immunol. 2004, 114, 915-921.

(10) Creticos, P.; Chen, Y.; Schroeder, J. New approaches in immunotherapy: allergen vaccination with immunostimulatory DNA. Immunol. Allergy Clin. North. Am. 2004, 24, 569-581.

(11) Enrique, E.; Pineda, F.; Malek, T.; Bartra, J.; Basagaña, M.; Tella, R.; Castelló, J. V.; Alonso, R.; de Mateo, J. A.; Cerdá-Trias, T.; San Miguel-Moncín, M.d.M.; Monzón, S.; García, M.; Palacios, R.; Cisteró-Bahíma, A. Sublingual immunotherapy for hazelnut food allergy: A randomized, double-blind, placebo-controlled study with a standardized hazelnut extract. J. Allergy Clin. Immunol. 2005, 116, 1073-1079.

(12) Meglio, P.; Bartone, E.; Plantamura, M.; Arabito, E.; Giampietro, P. G. A protocol for oral desensitization in children with IgEmediated cow's milk allergy. Allergy 2004, 59, 980-987.

(13) Leung, D. M.; Sampson, H.; Yunginger, J.; Burks, A. W., Jr.; Schneider, L.; Wortel, C.; Davis, F.; Hyun, J.; Shanahan, W., Jr. The TNX-901 Peanut Allergy Study Group, effect of anti-IgE therapy in patients with peanut allergy. N. Engl. J. Med. 2003, 348, 986-993.

(14) Singh, M. B.; Bhalla, L. P. Genetic engineering for removing food allergens from plants. Trends Plant Sci. 2008, 13, 257-260.

(15) Dodo, H. W.; Konan, K. N.; Chen, F. C.; Egnin, M.; Viquez, O. M. Alleviating peanut allergy using genetic engineering: the silencing of the immunodominant allergen Ara h 2 leads to its significant reduction and a decrease in peanut allergenicity. Plant Biotechnol. J. 2008, 6, 135-145.

(16) Mari, A.; Ronconi, A. M.; Mari, V. The impact of allergenic molecules in clinical allergy. How far is the "bench" from the "bed"? A 35-year retrospective analysis of papers from international scientific journals. 60th Annual Meeting American Academy of Allergy, Asthma and Immunology, San Francisco, CA, 2004. J. Allergy Clin. Immunol. 2004, 113.

(17) Mari, A.; Riccioli, D. The Allergome Web Site - a database of allergenic molecules. Aim, structure, and data of a web-based resource. 60th Annual Meeting American Academy of Allergy, Asthma and Immunology, San Francisco, CA, 2004. J. Allergy Clin. Immunol. 2004, 113.

(18) Mari, A.; Mari, V.; Ronconi, A. M.; Riccioli, D. Use of the Allergome database to study the impact of allergenic molecules in clinical allergy: a 35-year retrospective analysis of papers from 
international scientific journals. Congress Proceedings, XXIII Congress of the European Academy of Allergy and Clinical Immunology 2004, 190.

(19) Breiteneder, H.; Radauer, C. A classification of plant food allergens. J. Allergy Clin. Immunol. 2004, 113, 821-830.

(20) Sicherer, S. H.; Sampson, H. A.; Burks, A. W. Peanut and soy allergy: a clinical and therapeutic dilemma. Allergy 2000, 55, 515-521.

(21) Bock, S. A.; Munoz-Furlong, A.; Sampson, H. A. Fatalities due to anaphylactic reactions to foods. J. Allergy Clin. Immunol. 2001, 107, 191-193.

(22) Tada, Y.; Akagi, H.; Fujimura, T.; Matsuda, T. Effect of an antisense sequence on rice allergen genes comprising a multigene family. Breed. Sci. 2003, 53, 61-67.

(23) Le, L. Q.; Mahler, V.; Lorenz, Y.; Scheurer, S.; Biemelt, S.; Vieths, S.; Sonnewald, U. Reduced allergenicity of tomato fruits harvested from Lyc e 1-silenced transgenic tomato plants. J. Allergy Clin. Immunol. 2006, 118, 1176-1183.

(24) Le, L. Q.; Lorenz, Y.; Scheurer, S.; Fotisch, K.; Enrique, E.; Bartra, J.; Biemelt, S.; Vieths, S.; Sonnewald, U. Design of tomato fruits with reduced allergenicity by dsRNAi-mediated inhibition of ns-LTP (Lyc e 3) expression. Plant Biotechnol. 2006, 4, 231-242.

(25) Gilissen, L. J.; Bolhaar, S. T.; Matos, C. I.; Rouwendal, G. J.; Boone, M. J.; Krens, F. A.; Zuidmeer, L.; Van Leeuwen, A.; Akkerdaas, J.; Hoffmann-Sommergruber, K.; Knulst, A. C.; Bosch, D.; Van de Weg, W. E.; Van Ree, R. Silencing the major apple allergen Mal d 1 by using the RNA interference approach. J. Allergy Clin. Immunol. 2005, 115, 364-369.

(26) Jung, R.; Kinney, A. J. Hypoallergenic Transgenic Soybeans. U.S. Patent EP1266021, December 2002.

(27) Herman, E. M.; Helm, R. M.; Jung, R.; Kinney, A. J. Genetic modification removes an immunodominant allergen from soybean. Plant Physiol. 2003, 132, 36-43.

(28) Joseph, L.; Hymowitz, T.; Schmidt, M.; Herman, E. Evaluation of Glycine germplasm for nulls of the immunodominant allergen P34/ Gly m Bd 30k. Crop Sci. 2006, 46, 1755-1763.

(29) Chu, Y.; Faustinelli, P.; Ramos, M. L.; Hajduch, M.; Stevenson, S.; Thelen, J. J.; Maleki, S. J.; Ozias-Akins, P. Reduction of IgE binding and non-promotion of Aspergillus flavus fungal growth by simultaneously silencing Ara h 2 and Ara h 6 in peanut. J. Agric. Food Chem. 2008, 56, 11225-11233.

(30) Ramos, M. L.; Huntley, J. J.; Maleki, S. J.; Ozias-Akins, P. Identification and characterization of a hypoallergenic ortholog of Ara h 2.01. Plant Mol. Biol. 2009, 69, 325-335.

(31) Yaklich, R. W.; Helm, R. M.; Cockrell, G.; Herman, E. M. Analysis of the distribution of the major soybean seed allergens in a core collection of Glycine max accessions. Crop Sci. 1999, 39, 1444-1447.

(32) Kang, I.; Gallo, M.; Tillman, B. Distribution of allergen composition in peanut (Arachis hypogaea L.) and wild progenitor (Arachis) species. Crop Sci. 2007, 47, 997-1003.

(33) Koppelman, S. J.; Vlooswijk, R. A. A.; Knippels, L. M. J.; Hessing, M.; Knol, E. F.; van Reijsen, F. C.; Bruijnzeel-Koomen, C. A. F. M. Quantification of major peanut allergens Ara $\mathrm{h} 1$ and Ara $\mathrm{h} 2$ in the peanut varieties Runner, Spanish, Virginia, and Valencia, bred in different parts of the world. Allergy 2001, 56, 132-137.

(34) Comai, L.; Young, K.; Till, B. J.; Reynolds, S. H.; Greene, E. A.; Codomo, C. A.; Enns, L. C.; Johnson, J. E.; Burtner, C.; Odden, A. R.; Henikoff, S. Efficient discovery of DNA polymorphisms in natural populations by Ecotilling. Plant J. 2004, 37, 778-786.

(35) Kusaba, M. RNA interference in crop plants. Curr. Opin. Biotechnol. 2004, 15, 139-143.

(36) Hannon, G. J. RNA interference. Nature 2002, 418, 244-251.

(37) Takahashi, K.; Banba, H.; Kikuchi, A.; Ito, M.; Nakamura, S. An induced mutant line lacking the $\alpha$-subunit of $\beta$-conglycinin in soybean (Glycine max (L.) Merrill). Breed. Sci. 1994, 46, 65-66.

(38) Kinney, A.; Jung, R.; Herman, E. Cosuppression of the $\alpha$-subunits of $\beta$-conglycinin in transgenic soybean seeds induces the formation of endoplasmic reticulum-derived protein bodies. Plant Cell 2001, $13,1165-1178$.

(39) Takahashi, M.; Uematsu, Y.; Kashiwaba, K.; Yagasaki, K.; Hajika, M.; Matsunaga, R.; Komatsu, K.; Ishimoto, M. Accumulation of high levels of free amino acids in soybean seeds through integration of mutations conferring seed protein deficiency. Planta 2003, 217, $577-586$.

(40) Kitamura, K.; Kaizuma, N. Mutant strains with low level of 7S conglycinins. Jpn. J. Breed. 1981, 31, 353-359.

(41) Holzhauser, T.; Wackermann, O.; Ballmer-Weber, B. K.; Bindslev-Jensen, C.; Scibilia, J.; Perono-Garoffo, L.; Utsumi, S.; Poulsen, L. K.; Vieths, S. Soybean (Glycine max) allergy in Europe: Gly $\mathrm{m} 5$ ( $\beta$-conglycinin) and Gly $\mathrm{m} 6$ (glycinin) are potential diagnostic markers for severe allergic reactions to soy. J. Allergy Clin. Immunol. 2009, 123, 452-458 e4.

(42) Hajika, M.; Takahashi, M.; Sakai, S.; Igita, M. A new genotype of 7S globulin ( $\beta$-conglycinin) detected in wild soybean (Glycine soja Sieb. et Zucc.). Breed. Sci. 1996, 46, 385-386.

(43) Yagasaki, K.; Kalzuma, N.; Kitamura, K. Inheritance of glycinin subunits and characterization of glycinin molecules lacking the subunits in soybean (Glycine max (L.) Merr.). Breed. Sci. 1996, 46, $11-15$.

(44) Ogawa, T.; Bando, N.; Tsuji, H.; Okajima, H.; Nishikawa, K.; Sasaoka, K. Investigation of the IgE-binding proteins in soybeans by immunoblotting with the sera of the soybean-sensitive patients with atopic dermatitis. J. Nutr. Sci. Vitaminol. (Tokyo) 1991, 37, 555-565.

(45) Herman, E. Soybean allergenicity and suppression of the immunodominant allergen. Crop Sci. 2005, 45, 462-467.

(46) Bilyeu, K.; Ren, C.; Nguyen, H. T.; Herman, E.; Sleper, D. A. Association of a four-basepair insertion in the P34 gene with the lowallergen trait in soybean. The Plant Genome 2009, 2, 41-148.

(47) Bock, S. A.; Muñoz-Furlong, A.; Sampson, H. Further fatalities caused by anaphylactic reactions to food, 2001-2006. J. Allergy Clin. Immunol. 2007, 119, 1016-1018.

(48) Burks, W. Peanut allergy: a growing phenomenon. J. Clin. Invest. 2003, 111, 950-952.

(49) Stevenson, S. E.; Chu, Y.; Ozias-Akins, P.; Thelen, J. J. Validation of gel-free, label-free quantitative proteomics approaches: applications for seed allergen profiling. J. Proteomics 2009, 72, 555-66.

(50) Burks, A. W.; Williams, L. W.; Helm, R. M.; Connaughton, C.; Cockrell, G.; O'Brien, T. Identification of a major peanut allergen, Ara $\mathrm{h}$ I, in patients with atopic dermatitis and positive peanut challenges. J. Allergy Clin. Immunol. 1991, 88, 172-179.

(51) Rabjohn, P.; Helm, E.; Stanley, J. S.; West, C. M.; Sampson, H.; Burks, A. W.; Bannon, G. Molecular cloning and epitope analysis of the peanut allergen Ara h 3. J. Clin. Invest. 1999, 103, 535-542.

(52) Kleber-Janke, T.; Crameri, R.; Appenzeller, U.; Schlaak, M.; Becker, W. M. Selective cloning of peanut allergens, including profilin and $2 \mathrm{~S}$ albumins, by phage display technology. Int. Arch. Allergy Immunol. 1999, 119, 265-274.

(53) Burks, A. W.; Williams, L. W.; Helm, R. M.; Connaughton, C.; Cockrell, G.; O'Brien, T. Identification and characterization of a second major peanut allergen, Ara h II, with use of the sera of patients with atopic dermatitis and positive peanut challenge. J. Allergy Clin. Immunol. 1992, 90, 962-969.

(54) Asero, R.; Mistrello, G.; Roncarolo, D.; Amato, S.; Caldironi, G.; Barocci, F.; van Ree, R. Immunological cross-reactivity between lipid transfer proteins from botanically unrelated plant-derived foods: a clinical study. Allergy 2002, 57, 900-906.

(55) Mittag, D.; Akkerdaas, J.; Ballmer-Weber, B.; Vogel, L.; Wensing, M.; Becker, W.; Koppelman, S.; Knulst, A.; Helbling, A.; Hefle, S.; vanRee, R.; Vieths, S. Ara h 8, a Bet v 1-homologous allergen from peanut, is a major allergen in patients with combined birch pollen and peanut allergy. J. Allergy Clin. Immunol. 2004, 114, 1410-1417.

(56) Pons, L.; Chery, C.; Romano, A.; Namour, F.; Artesani, M.; Gueant, J. L. The $18 \mathrm{kDa}$ peanut oleosin is a candidate allergen for IgE-mediated reactions to peanuts. Allergy 2002, 57, 88-93.

(57) Tsuji, H.; Bando, N.; Hiemori, M.; Yamanishi, R.; Kimoto, M.; Nishikawa, K.; Ogawa, T. Purification of characterization of soybean allergen Gly m Bd 28K. Biosci., Biotechnol., Biochem. 1997, 61, 942-947.

(58) Ogawa, T.; Bando, N.; Tsuji, H.; Nishikawa, K.; Kitamura, K. $\alpha$-Subunit of $\beta$-conglycinin, an allergenic protein recognized by $\operatorname{IgE}$ antibodies of soybean-sensitive patients with atopic dermatitis. Biosci., Biotechnol., Biochem. 1995, 59, 831-833. 
(59) Helm, R. M.; Cockrell, G.; Connaughton, C.; Sampson, H. A.; Bannon, G. A.; Beilinson, V.; Nielsen, N. C.; Burks, A.W. A Soybean G2 glycinin allergen. 2. Epitope mapping and threedimensional modeling. Int. Arch. Allergy Immunol. 2000, 123, 213219.

(60) Zeece, M. G.; Beardslee, T. A.; Markwell, J. P.; Sarath, G. Identification of an IgE-binding region in soybean acidic glycinin G1. Food Agric. Immunol. 1999, 11, 83-83.

(61) Djurtoft, R.; Pedersen, H. S. A. B.; Barkholt, V. Studies of food allergens: soybean and egg proteins. Adv. Exp. Med. Biol. 1991, 289, 281-293.

(62) Beardslee, T. A.; Zeece, M. G.; Sarath, G.; Markwell, J. P. Soybean glycinin G1 acidic chain shares IgE epitopes with peanut allergen Ara h 3. Int. Arch. Allergy Immunol. 2000, 123, 299-307.

(63) Gu, X.; Beardslee, T.; Zeece, M.; Sarath, G.; Markwell, J. Identification of IgE-binding proteins in soy lecithin. Int. Arch. Allergy Immunol. 2001, 126, 218-225.

(64) González, R.; Varela, J.; Carreira, J.; Polo, F. Soybean hydrophobic protein and soybean hull allergy. Lancet 1995, 346, 48-49.

(65) Kleine-Tebbe, J.; Wangorsch, A.; Vogel, L.; Crowell, D.; Haustein, U.; Vieths, S. Severe oral allergy syndrome and anaphylactic reactions caused by a Bet v 1-related PR-10 protein in soybean, SAM22. J. Allergy Clin. Immunol. 2002, 110, 797-804.

(66) van Ree, R.; Voitenko, V.; van Leeuwen, W. A.; Aalberse, R. C. Profilin is a cross-reactive allergen in pollen and vegetable foods. Int Arch. Allergy Immunol. 1992, 98, 97-104.

(67) Rihs, H. P.; Chen, Z.; Ruëff, F.; Petersen, A.; Rozynek, P.; Heimann, H.; Baur, X. IgE binding of the recombinant allergen soybean profilin (rGly $\mathrm{m} \mathrm{3}$ ) is mediated by conformational epitopes. J. Allergy Clin. Immunol. 1999, 104, 1293-1301.

(68) Tsuji, H. N.; Okada, R.; Yamanishi, N.; Bando, M.; Kimoto, M.; Ogawa, T. Measurement of Gly $\mathrm{m} \mathrm{Bd} \mathrm{30K,} \mathrm{a} \mathrm{major} \mathrm{soybean} \mathrm{allergen,}$ in soybean products by a sandwich enzyme-linked immunosorbent assay. Biosci., Biotechnol., Biochem. 1995, 59, 150-151.

(69) Moroz, L. A.; Yang, W. H. Kunitz soybean trypsin inhibitor: a specific allergen in food anaphylaxis. N. Engl. J. Med. 1980, 302, $1126-1128$.

(70) Riascos, J. J.; Burks, A. W.; Pons, L. A.; Weissinger, A. K.; Weissinger, S. M. Identification of a soybean seed biotinylated protein as a novel allergen. J. Allergy Clin. Immunol. 2009, 123, S24.

(71) Codina, R.; Lockey, R. F.; Fernandez-Caldas, E.; Rama, R. Purification and characterization of a soybean hull allergen responsible for the Barcelona asthma outbreaks. II. Purification and sequencing of the Gly m 2 allergen. Clin. Exp. Allergy 1997, 27, 424-430.

(72) Xiang, P.; Baird, L. M.; Jung, R.; Zeece, M. G.; Markwell, J.; Sarath, G. P39, a novel soybean protein allergen, belongs to a plant-specific protein family and is present in protein storage vacuoles. J. Agric. Food Chem. 2008, 56, 2266-2272.

(73) Codina, R.; Ardusso, L.; Lockey, R. F.; Crisci, C. D.; Jaen, C.; Bertoya, N. H. Identification of the soybean hull allergens involved in sensitization to soybean dust in a rural population from Argentina and N-terminal sequence of a major $50 \mathrm{KD}$ allergen. Clin. Exp. Allergy 2002, 32, 1059-63.

(74) Sánchez-Monge, R.; Pascual, C. Y.; Diaz-Perales, A.; FernandezCrespo, J.; Martin-Esteban, M.; Salcedo, G. Isolation and characterization of relevant allergens from boiled lentils. J. Allergy Clin. Immunol. 2000, 106, 955-961.

(75) Mittag, D.; Vieths, S.; Vogel, L.; Wagner-Loew, D.; Starke, A.; Hunziker, P.; Becker, W.-.; Ballmer-Weber, B. K. Birch pollenrelated food allergy to legumes: identification and characterization of the Bet v 1 homologue in mungbean (Vigna radiata), Vig r 1. Clin. Exp. Allergy 2005, 35, 1049-1055.

(76) Sánchez-Monge, R.; Blanco, C.; Perales, A.; Collada, C.; Carrillo, T.; Aragoncillo, C.; Salcedo, G.; Class, I Chitinases, the panallergens responsible for the latex-fruit syndrome, are induced by ethylene treatment and inactivated by heating. J. Allergy Clin. Immunol. 2000, 106, 190-195.

(77) Rao, T. R.; Rao, D. N.; Kotilingam, K.; Athota, R. R. Isolation and characterization of allergens from the seeds of Vigna sinensis. Asian Pac. J. Allergy Immunol. 2000, 18, 9-14.

(78) Vioque, J.; Sanchez-Vioque, R.; Clemente, A.; Pedroche, J.; Bautista, J.; Millan, F. Purification and partial characterization of chickpea 2S albumin. J. Agric. Food Chem. 1999, 47, 1405-1409.

(79) Sánchez-Monge, R.; Lopez-Torrejon, G.; Pascual, C. Y.; Varela, J.; Martin-Esteban, M.; Salcedo, G. Vicilin and convicilin are potential major allergens from pea. Clin. Exp. Allergy 2004, 34, 1747-1753.

(80) Magni, C.; Herndl, A.; Sironi, E.; Scarafoni, A.; Ballabio, C.; Restani, P.; Bernardini, R.; Novembre, E.; Vierucci, A.; Duranti, $\mathrm{M}$. One- and two-dimensional electrophoretic identification of IgEbinding polypeptides of Lupinus albus and other legume seeds. J. Agric. Food Chem. 2005, 53, 4567-4571.

(81) Peeters, K. B. M.; Nordlee, J.; Penninks, A.; Chen, L.; Goodman, R.; Bruijnzeel-Koomen, C. F. M.; Hefle, S.; Taylor, S.; Knulst, A. Lupine allergy: not simply cross-reactivity with peanut or soy. J. Allergy Clin. Immunol. 2007, 120, 647-653.

(82) Compés, E.; Hernández, E.; Quirce, S.; Palomares, O.; Rodríguez, R.; Cuesta, J.; Sastre, J.; Villalba, M. Hypersensitivity to black locust (Robinia pseudoacacia) pollen: "allergy mirages. Ann. Allergy Asthma Immunol. 2006, 96, 586-592.

Received for review July 21, 2009. Revised manuscript received October 20, 2009. Accepted October 28, 2009. 